\title{
Association Between Body Mass Index, Dental Caries (DMFT \& PUFA) and Socioeconomic Status in 12 to 15 Year Old School Children
}

AIM: The aim of the study was to evaluate the association between body mass index, dental caries (DMFT), untreated dental caries (PUFA) and socioeconomic status in 12 to 15 year old school children.

MATERIAL AND METHODS: The study sample consisted of 800 children aged 12 to 15 years, who were selected from 8 schools located in the district-Panchkula (Haryana). Intraoral examination was done for assessment of dental caries by using DMFT index (WHO, 2013).The clinical manifestations of untreated dental caries were assessed visually by using the PUFA index (2010). Socioeconomic status of children was assessed by using Kuppuswami's socioeconomic scale 2016. After one week, anthropometric measurements of children were taken to calculate the body mass index (BMI) of children.

RESULTS: Among 800 school children, 503 (62.9\%) children had dental caries. The body mass index (BMI) of children was weakly correlated with DMFT $(\mathrm{r}=0.285)$ and PUFA $(\mathrm{r}=0.109)$ whereas average correlation was found between BMI and SES $(\mathrm{r}=0.424)$. On applying chi-square test, a statistical significant correlation was found between BMI and DMFT ( $<<0.01$ ), BMI and PUFA (p<0.01) and BMI and SES $(\mathrm{p}<0.01)$. SES of children was weakly correlated with DMFT $(\mathrm{r}=0.216)$ but no correlation was found between SES and PUFA $(\mathrm{r}=0.052, \mathrm{p}=0.145)$.

CONCLUSION: The study concluded that a significant but weak positive correlation was seen between dental caries and BMI. A significantly positive correlation was found between PUFA and BMI. The severity of dental caries increased with increase in BMI. No correlation was found between PUFA and SES.

KEYWORDS: Body mass index, Dental caries (DMFT, PUFA), Socioeconomic status

\section{INTRODUCTION}

In the present scenario, obesity, stunting, malnutrition and dental diseases are major public health challenges globally. Dental caries is a most prevalent multi-factorial infectious disease which affects the overall health of an individual. Risk of dental caries is evaluated by analyzing and integrating several causative factors such as microbial plaque, diet, bacterial and salivary activity. ${ }^{1}$ There is a strong association between malnutrition and increased prevalence of dental caries. However, the association is often explained by the common risk factors between dental caries and malnutrition, for e.g. diet, socioeconomic status, education, urbanization, eating habits and lifestyle. ${ }^{2}$

The people who have an unbalanced diet that includes sugary and calorie dense food with low nutritional value, usually suffer from both malnutrition and dental caries. ${ }^{3}$ It is also associated with enhanced susceptibility to caries because of impaired saliva secretion due to salivary glandular hypo-function and saliva compositional changes thereby increasing cariogenic activity. ${ }^{4}$
Caries and its consequences restrict the quantity and variety of food eaten leading to inadequate food intake following under nutrition and decreased BMI. ${ }^{5}$ Pulpitis, periapical abscesses, alveolar abscess, periapical granuloma or periapical cyst share the same etiology of being untreated by dental caries. ${ }^{6}$ It may affect quality of children's life because of pain and discomfort which could leads to acute and chronic infections, oral mucosal conditions and reduced food intake and sleep. Untreated dental caries, which has been assessed using PUFA /pufa indices, have thus been linked to BMI for a particular age. ${ }^{7}$

To assess the nutritional status whether overnutrition or undernutrition, anthropometry is the most basic tool which is universally applicable, inexpensive and non-invasive method. ${ }^{8,9}$ Among anthropometric measures, BMI is one of the most reliable methods that identify changes in weight for height with units for underweight, normal weight and overweight. ${ }^{10}$

Another variable that influences the relation of 
dental caries and BMI is socioeconomic status (SES). The relationship between SES and incidence and prevalence of diseases is well established."

Thus, the aim of present study was to assess the association between dental caries (DMFT and PUFA), BMI and socioeconomic status in school children, aged 12-15 years.

\section{MATERIAL AND METHODS}

The study sample consisted of 800 children aged 12 to 15 years, who were selected from 8 schools located in the district-Panchkula (Haryana). Prior to proceeding with the study, approval was obtained from the ethical committee of B.R.S. Institute of Medical Sciences, Dental College and Hospital, Village Sultanpur, Panchkula, Haryana. Children from each class were selected by using systematic random sampling i.e. every third child from the attendance register was included in the study. If the selected child was absent on the day of examination, then the next roll number in the attendance register was included.

A two-phase random sampling strategy was used to ensure equal representativeness of the total population under study:-

- In the first phase, schools were selected randomly from the list provided by the Department of Secondary Education, Panchkula (Haryana).

- The second phase involved seeking permission from the administrative authorities of the selected schools to conduct the study.

All children in the study age range (i.e. 12 to 15 years) were provided with a letter of written consent to be signed by their parents Additionally, a document was sent to the parents which consisted of questions regarding their family's socio-demographic details such as the parent's occupation and education level, as well as, the family's monthly income (Kuppuswami's socioeconomic scale 2016).12 On the following day, only those children with consent signed by their parents were enrolled in the study.

\section{Inclusion criteria}

- Children aged 12 to 15 year, born between years 2001-2004

- Children free of any systemic disease or medically compromising condition

- Children from whom signed written consent by their parents was obtained
- Children who were cooperative and able to follow up after one week

\section{Exclusion criteria}

- Inadequate co-operation by the child during the examination

- Children who did not have signed written consent by their parents

Prior to start of the study, the examiner received theoretical and clinical calibration training for using DMFT and PUFA indices. The examiner was calibrated for intraoral examination and anthropometric measurements by repeated sessions of training under a supervisor. Questionnaire completion and intraoral assessment for dental caries (DMFT and PUFA) was done by both the principal investigator (examiner) and supervisor. After one week, all patients were recalled for the assessment of anthropometric measurements i.e. body mass index by measuring height and weight of the children.

All the children were examined by a single trained and calibrated examiner in a class room of the school and assisted by one trained assistant to record the data. The children were examined on school premises, seated on the ordinary chairs using a lightweight portable examination light. Dental caries status of all the children was assessed using a sterilized mouth mirror (API) and CPI probe according to WHO criteria (2013) by using DMFT index.13 The clinical manifestations of untreated dental caries were assessed visually by using the PUFA index (2010).14 The index was recorded and scored for the presence of a visible pulp (P), ulceration of oral mucosa due to root fragments $(\mathrm{U})$, a fistula (F) or an abscess (A).

In order to blind the study, the anthropometric measurements was performed a week after the clinical examination. The height was measured to the nearest $0.1 \mathrm{~cm}$, using a stadiometer. The child was made to stand barefoot and erect on the base of the stadiometer to get an exact measure of height. The weight of the child was measured to the nearest $0.1 \mathrm{~kg}$ by using pin moving weighing machine. The two variables were then utilized to calculate BMI using the formula; weight/height $(\mathrm{kg} / \mathrm{m} 2)$ for the particular age of the subject. The obtained BMI values for each subject were then compared to revised growth charts provided by Indian Academy 
of Pediatrics (IAP, 2015) to categorize the children as obese, overweight, normal or underweight. ${ }^{15}$

\section{Statistical analysis:}

The data were collected and analyzed with statistical package for the social sciences (SPSS Inc., Chicago, IL, version 22.0 for Windows) statistics application. Descriptive statistics, frequency distributions and contingency coefficient was used for determining associations between variables and measuring the central tendencies. Spearman's correlation coefficient was used to detect the association of one variable to other. Chi square test was used to assess the difference between socio-demographic factors in relation to BMI. Categorical data are presented as numbers and statistical test of significance was computed so that a $\mathrm{p}$ value $<0.05$ was considered significant.

\section{RESULTS}

Table 1 shows the distribution of study subjects according to socioeconomic status (SES). Almost half of the children i.e. 399 (49.9\%) belonged to upper middle class followed by 271 (34\%) to lower middle class and 115 (14.4\%) to upper lower class. Hence, majority of children (671) belonged to middle

\begin{tabular}{|c|c|c|}
\hline SOCIOECONOMIC STATUS & FREQUENCY (N) & $(\%)$ \\
\hline UPPER CLASS & 13 & 1.6 \\
\hline UPPER MIDDLE CLASS & 399 & 49.9 \\
\hline LOWER MIDDLE CLASS & 272 & 34 \\
\hline UPPER LOWER CLASS & 115 & 14.4 \\
\hline LOWER CLASS & 1 & 0.1 \\
\hline
\end{tabular}

Table 1. Distribution of socioeconomic status of children

class; both upper and lower.

Table 2 shows the BMI values among study participants varied from 13 to $31 \mathrm{~kg} / \mathrm{m} 2$ with the mean BMI of $20.4 \pm 3.4 \mathrm{~kg} / \mathrm{m}^{2}$. Normal body weight was recorded in $54.9 \%$ of total study participants followed by participants at risk of obesity $(17.8 \%)$, risk of overweight (13.6\%) and underweight (10.3\%). Normal body weight was the most common type of body weight category amongst all the children while obese was the least occurring one.

\begin{tabular}{|c|c|c|}
\hline $\begin{array}{l}\text { Body Mass } \\
\text { Index }\end{array}$ & Frequency $\mathbf{N}$ & $(\%)$ \\
\hline Underweight & 82 & 10.3 \\
\hline Normal & 439 & 54.9 \\
\hline $\begin{array}{l}\text { Risk of } \\
\text { overweight }\end{array}$ & 109 & 13.6 \\
\hline $\begin{array}{l}\text { Risk of } \\
\text { obesity }\end{array}$ & 142 & 17.8 \\
\hline Obese & 28 & $3 \cdot 5$ \\
\hline Total & 800 & 100 \\
\hline
\end{tabular}

Table 2. Distribution of Body Mass Index
Among 800 school children, 503 (62.9\%) children had dental caries and 297 (37.1\%) had no dental caries (Table-3). The mean DMFT was found to be $1.91 \pm 2.17$ with more number of decayed teeth (DT) $1.74 \pm 1.9$ as compared to missing teeth (MT) $0.01 \pm 0.354$ and filled teeth (FT) $0.17 \pm 0.68$.

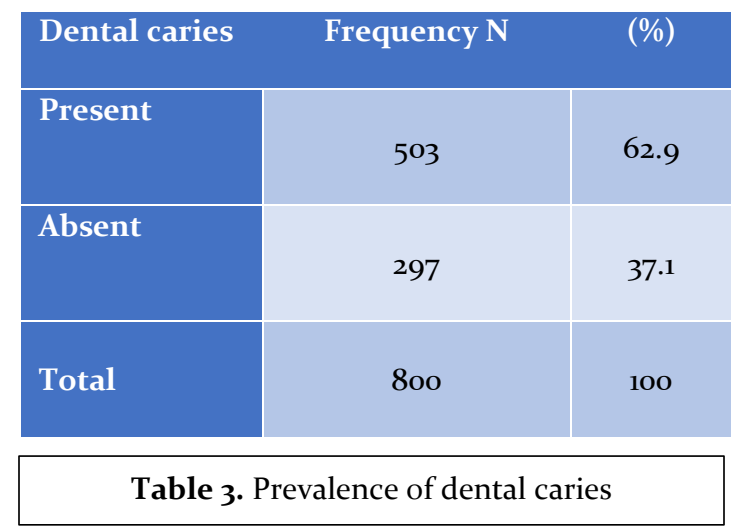

The overall prevalence of PUFA in study participants was $7.1 \%$ which was very low. The mean was found to be $0.11 \pm 0.436$. (Table-4) 


\begin{tabular}{|c|c|c|c|c|c|}
\hline & $\begin{array}{c}\mathbf{P} \\
\mathbf{N} \%\end{array}$ & $\begin{array}{c}\mathrm{U} \\
\mathrm{N} \%\end{array}$ & $\begin{array}{c}\mathbf{F} \\
\mathbf{N} \%\end{array}$ & $\begin{array}{c}\mathrm{A} \\
\mathrm{N} \%\end{array}$ & $\begin{array}{l}\text { PUFA } \\
\text { N (\%) }\end{array}$ \\
\hline Absence of condition & $757(94.6)$ & 800 & 800 & 774 (96.8) & $743(92.9)$ \\
\hline Presence of condition & $43(5.4)$ & o & o & $26(3.3)$ & $57(7.1)$ \\
\hline
\end{tabular}

Table 4. Prevalence of untreated dental caries

Spearman's correlation coefficient (r) was used to find out the correlation of BMI with DMFT, SES and PUFA. It was found that the body mass index (BMI) of children was weakly correlated with DMFT ( $\mathrm{r}=0.285)$ and PUFA ( $\mathrm{r}=0.109)$ whereas average correlation was found between BMI and SES $(r=0.424)$. On applying chi-square test, a statistical significant correlation was found between BMI and DMFT ( $\mathrm{p}<\mathrm{0.01})$, BMI and PUFA $(\mathrm{p}<0.01)$ and BMI and SES $(\mathrm{p}<0.01)($ Table-5).
The presence and severity of dental caries increased with increasing BMI and socioeconomic status SES of children was weakly correlated with DMFT $(r=0.216)$ but no correlation was found between SES and PUFA $(\mathrm{r}=0.052, \mathrm{p}=0.145)$. On applying the chi-square test, a statistical significant correlation was found between SES and DMFT $(\mathrm{p}<0.01)$ (Table-6). With increasing the level of socioeconomic status of children the prevalence of dental caries was also increasing.

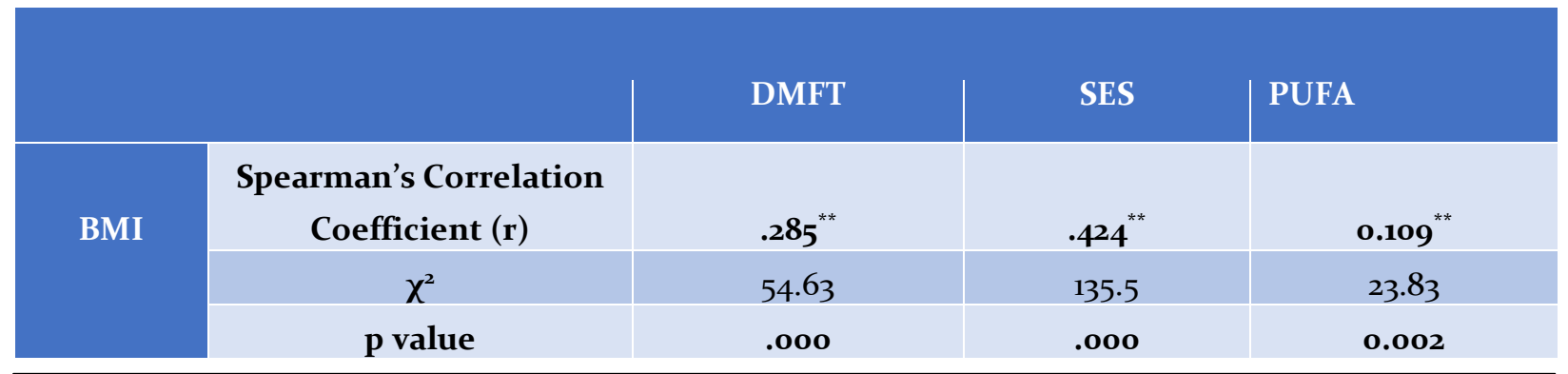

Table 5. Correlation of BMI with DMFT, PUFA and SES using non-parametric test (Chi square test). ${ }^{*}$ Correlation is significant at the 0.05 level (2-tailed) **: Correlation is significant at the 0.01 level (2-tailed).

\begin{tabular}{|c|c|c|c|}
\hline & & $\begin{array}{c}\text { Dental caries } \\
\text { (DMFT) }\end{array}$ & PUFA \\
\hline \multirow{3}{*}{ SES } & Spearman's Correlation Coefficient ( $r$ ) & $.216^{* *}$ & .052 \\
\hline & $x^{2}$ & 32.71 & 1.068 \\
\hline & p value & .000 & 0.145 \\
\hline
\end{tabular}

Table 6. Correlation of SES with dental caries (DMFT) and PUFA using non-parametric test (chi square test) ${ }^{*}$ Correlation is significant at the 0.05 level (2-tailed) ${ }^{* *}$ : Correlation is significant at the 0.01 level (2-tailed).

\section{DISCUSSION}

The present study was undertaken to assess the association between body mass index, oral health and lifestyle factors in 12-15 year old school children of Panchkula District, Haryana. Children in the age group of 12 and 15 years were chosen for this study, as these are global monitoring ages for dental caries as mentioned by WHO for international comparisons and monitoring of disease trends. ${ }^{13}$

Intraoral examination for dental caries status, 
untreated dental caries, and anthropometric measurements were done for all the children included in the study.

In the present study, BMI values among study participants varied from 13 to $31 \mathrm{~kg} / \mathrm{m}^{2}$ with the mean of $20.4 \pm 3.4 \mathrm{~kg} / \mathrm{m}^{2}$. The majority of the participants

(54.9\%) were in normal weight category.

In the socioeconomic status, maximum number of children i.e. 399 (49.9\%) belonged to upper middle class followed by 272 (34\%) who belonged to lower middle class, 115 (14.4\%) upper lower class, 13 (1.6\%) upper class and minimum (o.1\%) belonged to lower class.

The mean DMFT was found to be $1.91 \pm 2.17$ in which more number of decayed teeth (DT) with mean $1.74 \pm 1.9$ were present as compared to missing teeth (MT) $0.01 \pm 0.354$ and filled teeth (FT) $0.17 \pm 0.68$.

A statistically significant but weak positive correlation was found between BMI and dental caries in the present study $(\mathrm{r}=0.285, \mathrm{p}<0.01)$. A higher percentage of dental caries (89.3\%) was found in children belonging to category of obesity group followed by risk of obesity group (85.9\%), then in underweight group (64.6\%), risk of overweight group $(57.8 \%)$ and least in normal weight group children (54.7\%).

Various other studies by Hilgers et al. $(2006)^{16}$, Kantovitz KR (2006) $)^{17}$, Willerhausen B (2007) ${ }^{18}$, Marshall TA $(2007)^{19}$, Gerdin et al $(2008)^{20}$, and Costacurta et al (2011) ${ }^{9}$ have also found a positive correlation between BMI and dental caries. Results of these studies were in accordance with those of the present study, showing that children who are overweight or obese have high level of dental caries and this may be attributed to the high level of consumption of soda and other energy-dense foods by overweight children.

A study done by Wali A (2016) reported a statistically significant correlation between BMI and DMFT scores which may be due to the patients having irregular dietary pattern, lack of knowledge of oral hygiene and infrequent visits to dentist. ${ }^{21}$ However, not all studies have found a positive correlation between BMI and dental caries; some studies suggest that there is no relationship between BMI and dental caries e.g. Macek and Mitola (2006) ${ }^{22}$, Sadeghi M $(2007)^{23}$, Almerich-Torres T (2017) ${ }^{11}$ and others showed an inverse relationship e.g. Oliveria LB (2008) $)^{24}$, Benzain H (2011) $)^{25}$, Bafti LS $(2015)^{26}$ and Mangukia DH (2017). ${ }^{27}$ Marshall et al (2007) found that neither obesity increase risk of caries, nor caries increase risk of obesity but rather common risk factors increased the likelihood of both the diseases. ${ }^{28}$

The relationship between SES, BMI and dental caries was also evaluated. A statistically significant high positive correlation was found between SES and BMI $(\mathrm{r}=0.424, \mathrm{p}<0.01)$ and between SES and dental caries $(\mathrm{r}=0.216, \mathrm{p}<0.01)$. In the present study most of the heavy weight children (obese and at risk of obesity) belonged to upper and lower middle class of socioeconomic status and more dental caries was found in upper middle class. The increased caries and increased weight may be due to the mother's low education level and high family income. Less educated mothers were more likely to consume soft drinks and sweets and also permit their children to consume the same than highly educated mothers. Similar results were also found in studies done by Gupta DK et al (2011) ${ }^{29}$, Khaldikar et al (2012) ${ }^{30}$ Sakeenabi et al (2012) ${ }^{31}$ and Begum et al (2014). ${ }^{32}$

On contrary to this study, an inverse relation between socioeconomic status and dental caries has been found by various other studies done by ALHosani E (1998)33, Hallett KB (2003) ${ }^{34}$, Harris R (2004) $)^{35}$, Peres et al (2005) $)^{36}$, Sudha P (2005) ${ }^{37}$ and Oliveira LB $(2008)^{24}$. The reason for this could be low level of mothers' education and low family income which could be one of the factor for rare accessibility for dentist and unaffordability towards dental treatment.

No correlation was found between dental caries and SES in a study done by Masiga et al (1993) due to unequal distribution of SES classes and variation in measuring socioeconomic status. ${ }^{38}$

In the current study, the overall PUFA prevalence was low in the study participants i.e. $7.1 \%$, only 57 children were found with presence of oral conditions due to untreated caries. The mean PUFA was $0.11 \pm 0.42$, with the $\mathrm{P}$ component i.e. pulp involvement being most common than other components i.e. abscess formation (A), ulceration $(\mathrm{U})$ and fistula $(\mathrm{F})$. The low prevalence of untreated caries in permanent teeth might be due to the age group selected in the current study i.e. 12-15 years. At 
this age, the recent transition has occurred from primary dentition stage to permanent dentition stage providing not enough time to develop dental caries, severity or progression of dental caries in the newly erupted teeth as also stated by Khan SQ (2013). 39

Other studies done by Kamran R (2017) ${ }^{40}$, Shahbong $\mathrm{R}(2013)^{41}$ and Dixit P (2013) $)^{42}$ showed even higher prevalence of PUFA i.e. $21.8 \%, 37 \%$ and $31 \%$ respectively. According to Kamran R (2017) ${ }^{40}$ and Shahbong R (2013) ${ }^{41}$, a higher prevalence of PUFA was because firstly, both these studies were conducted on orphanage children who had free access to sugary foods and sweetened drinks that lead to caries and secondly, due to negligence, lack of supervision and reinforcement of authorities of orphanages. According to Dixit P (2013) ${ }^{42}$ the reason for high prevalence of PUFA in their study was the lack of access to affordable health care services.

In PUFA index, there is no scoring pertaining to the severity of pain as the consequence of untreated dental caries. This drawback can be considered as one of the limitation of the index. In various studies pain parameter as the consequence of dental diseases itself or the outcomes of treatment intervention has been evaluated. ${ }^{43}$ However, PUFA index is only relied on objective signs, the subjective parameters such as pain and discomfort have not been considered. In the present study also no pain parameters were recorded. ${ }^{44}$ Hence, the correlation between PUFA and BMI can be because of the painless carious exposure and self medication which might have avoided the inability to eat, thereby not decreasing the BMI of the individuals.

The results were in accordance with the study conducted by Chala S (2017) which showed a Ushaped association of BMI and dental caries which means that an increased rate of untreated tooth decay was associated with both under and overweight. ${ }^{45}$

\section{CONCLUSION}

In this study population, BMI, dental caries, PUFA, periodontal status, socioeconomic status and life style (oral hygiene and dietary habits) were assessed and correlated. A significant but weak positive correlation was found between dental caries and BMI. A significantly positive correlation was found between PUFA and BMI. The severity of dental caries increased with increase in BMI. No correlation was found between PUFA and SES. BMI of children was positively correlated with SES and untreated dental caries (PUFA), which reveals that children with high BMI belonged to upper middle class society and children with low BMI belonged to lower middle class. All the factors considered in the study are interrelated and health promoting strategies will only improve children wellbeing and provide them with good quality of life.

The population should be made aware on the preventive and restorative care of teeth for better oral hygiene. This can be done at community and individual level. As a member of dental health team, it is critical that dentist maintain awareness of these problems and participate in assessment and prevention of children's obesity and dental caries.

\section{REFERENCES}

1. Gupta P, Gupta N, Singh HP. Prevalence of dental caries in relation to body mass index, daily sugar intake, and oral hygiene status in 12-year-old school children in Mathura City: A pilot study. Int J Pediatr. 2014;12:1-5.

2. Shakya A, Shenoy R, Rao A. Correlation between malnutrition and dental caries in children. J Nepal Paediatr Soc. 2013;33(2):99-102.

3. Costacurta M, DiRenzo L, Sicuro L, Gratteri S, de Lorenzo A, Docimo R. Dental caries and childhood obesity: analysis of food intakes, lifestyle. Eur J Paediatr Dent. 2014;15(4):343-8.

4. Sheetal A, Hiremath VK, Patil AG, Sajjansetty S, Kumar SR. Malnutrition and its oral outcome- A review. J Clin Diagn Res. 2013;7(1):178-80.

5. Cinar $A B$, Murtomaa $H$. Interrelation between obesity, oral health and life-style factors among Turkish school children. Clin Oral Investig. 2011;15(2):177-84.

6. Dua R, Jindal R, Kaur D, Aggarwal N. Correlation between PUFA/pufa scores and BMI-for age in rural Indian children. Indian J Oral Sci. 2014;5(1):21-6.

7. Graund K, Goddon I, Schuler IM, Lehmann T, Weltzien RH. Clinical consequences of untreated dental caries in German 5-and 8-year-olds. BMC Oral Health. 2015;15(1):140.

8. World Health Organization. Physical status: the use and interpretation of anthropometry. Report of a WHO Expert Committee. World Health Organ Tech Rep Ser. 1995;854:1-452.

9. Costacurta M, Renzo LD, Bianchi A, Fabiocchi F, Lorenzo AD, Docimo R. Obesity and dental caries in 
paediatric patients. Eur J of Paediatr Dent. 2011;12(2):112-6.

10. Chung S. Body mass index and body composition scaling to height in children and adolescent. Ann Pediatr Endocrinol Metab. 2015;20(3):125-29.

11. Almerich-Torres T, Montiel-Company JM, BellotArcís C, Almerich-Silla JM. Relationship between caries, body mass index and social class in Spanish children. Gac Sanit. 2017;31(6):499-504.

12. Shaikh Z, Pathak R. Revised Kuppuswamy and B $G$ Prasad socio-economic scales for 2016. Int J Community Med Public Health. 2017;4(4):997-9.

13. Oral health surveys. Geneva: World health organization; 2013.

14. Monse B, Heinrich-Weltzien R, Benzian $\mathrm{H}$, Holmgren C, Ven Palenstein Helderman W. PUFAAn index of clinical consequences of untreated dental caries. Community Dent Oral Epidemiol. 2010;38(1):77-82.

15. Khaldikar V, Yadav S, Agarwal K, Tamboli S, Cherian A et al. Revised IAP growth charts for height, weight and body mass index for 5- to 18 -yearold Indian children. Indian Pediatr. 2015;52(1):47-55. 16. Hilgers KK, Kinane DF, Scheetz JP. Association between childhood obesity and smooth-surface caries in posterior teeth: a preliminary study. Pediatr Dent. 2006;28(1):23-8.

17. Kantovitz KR, Pascon FM, Rontani RM, Gaviao MB. Obesity and dental caries-A systematic review. Oral Health Prev Dent. 2006;4(2):137-44.

18. Willerhausen B, Blettner M, Kasaj A, Hohenfellner K. Association between body mass index and dental health in 1,290 children of elementary schools in a German city. Clin Oral Investig. 2007;11(3):195-200.

19. Marshall TA, Eichenberger-Gilmore JM, Broffitt BA, Warren JJ, Levy SM. Dental caries and childhood obesity: roles of diet and socioeconomic status. Community Dent Oral Epidemiol. 2007;35(6):44958.

20. Gerdin EW, Angbratt M, Aronsson K, Eriksson E, Johansson I. Dental caries and body mass index by socio-economic status in Swedish children. Community Dent Oral Epidemiol. 2008;36(5):45965.

21. Wali A, Siddiqui TM, Yousuf S, Moud F. Correlation of body mass index and dental caries in patients attending Baqai dental college, Karachi, Pakistan. J Adv Oral Res. 2016;7(3):15-9.

22. Macek MD, Mitola DJ. Exploring the association between overweight and dental caries among US children. Pediatr Dent. 2006;28(4):375-80.
23. Sadeghi M, Alizadeh F. Association between dental caries and body mass index-for-age among 611-year-old children in Isfahan in 2007. J Dent Res, Dent Clin, Dent Prospects. 2007;1(3):119-24.

24. Oliveira LB, Sheiham A, Bonecker M. Exploring the association of dental caries with social factors and nutritional status in Brazilian preschool children. Eur J Oral Sci. 2008;116(1):37-43.

25. Benzian $\mathrm{H}$, Monse B, Heinrich-Weltzien R, Hobdell M, Mulder J, van Palenstein Helderman W. Untreated severe dental decay: a neglected determinant of low Body Mass Index in 12-year-old Filipino Children. BMC Public Health. 2011;11:1-9.

26. Bafti LS, Hashemipour MA, Poureslami H, Hoseinian Z. Relationship between body mass index and tooth decay in a population of 3-6-year-old children in Iran. Int J Dent. 2015;2015:126530.

27. Mangukia H, Arora R, Dogra S. Relationship between body mass index, dental caries and socioeconomic status in a population of 4-14 year old children in Udaipur city. J Dent Med Sci. 2017;16(3):99-103.

28. Tripathi S, Kiran K, Kamla BK. Relationship between obesity and dental caries in children. J Int Oral Health. 2010;2(4):65-72.

29. Khan SQ, Khan NB, Arrejaie AS. Dental caries. A Meta analysis on a Saudi population. Saudi Med J. 2013;34(7):744-9.

30. Marinho VC, Higgins JP, Logan S, Sheiham A. Fluoride gels for preventing dental caries in children and adolescents. Cochrane Database Syst Rev. 2002;(2):CDoo2280.

31. Sakeenabi B, Swamy HS, Mohammed RN. Association between obesity, Dental caries and socioeconomic status in 6 and 13-year-old school children. Oral Health Prev Dent. 2012;10(3):231-41.

32. Begum $M$, Nagamalleshwari $M$, Srinivas $P$, Gadagi JS, Gadde P, Jyothirmai K. Is body mass index truly related to dental caries? Survey on predisposing factors for overweight among Indian school children. Dent Hypotheses. 2014;5:150-4.

33. Al-Hosani E, Rugg-Gunn A. Combination of low parental educational attainment and high parental income related to high caries experience in preschool children in Abu Dhabi. Community Dent Oral Epidemiol. 1998;26(1):31-6.

34. Hallett KB, ORourke PK. Social and behaviour determinants of early childhood caries. Aust Dent J. 2003;48:27-33.

35. Harris R, Nicoll AD, Adair PM, Pine CM. Risk factors for dental caries in young children: a systematic review of the literature. Community Dent Health. 2004;21:71-85. 
36. Vereecken C, Keukelier E, Maes L. Influence of mother's educational level on food parenting practices and food habits of young children. Appetite. 2004;43(1):93-103.

37. Sudha P, Bhasin S, Anegundi RT. Prevalence of dental caries among 5-13-yearold children of Mangalore city. J Indian Soc Pedod Prev Dent. 2005;23:74-9.

38. Masiga MA, Holt RD. The prevalence of dental caries and gingivitis and their relationship to social class amongst nursery-school children in Nairobi, Kenya. Int J Paediatr Dent. 1993;3(3):135-40.

39. Khan SQ, Khan NB, Arrejaie AS. Dental caries. A Meta analysis on a Saudi population. Saudi Med J. 2013;34(7):744-9.

40. Kamran R, Farooq W, Faisal MR, Jahangir F. Clinical consequences of untreated dental caries assessed using PUFA index and its covariates in children residing in orphanages of Pakistan. BMC Oral Health. 2017;17:1-7.

41. Shanbhog R, Godhi BS, Nandlal B, Kumar SS, Raju V, Rashmi S. Clinical consequences of untreated dental caries evaluated using PUFA index in orphanage children from India. J Int Oral Health. 2013;5(5):1-9.

42. Dixit PL, Shakya A, Shrestha M, Shrestha A. Dental caries prevalence, oral health knowledge and practice among indigenous Chepang school children of Nepal. BMC oral Health. 2013;13:1-5.

43. Ramazani M, Hamidi MR, Moghaddamnia AA, Ramazani N, Zarenejad N. The prophylactic effects of zintoma and ibuprofen on postendodontic pain of molars with irreversible pulpitis: A randomized clinical trial. Iran Endod J. 2013;8(3):129-34.

44. Ramazani N, Rezaei S. Evaluation of the prevalence of clinical consequences of untreated dental caries using PUFA/pufa index in a group of Iranian children. Iran J Pediatr. 2017;27(1):1-6.

45. Chala S, Aidouni ME, Abouqal R and Abdallaoui F. U-shaped association between untreated caries and body mass index in adults at Rabat dental University hospital, Morocco: cross sectional study. BMC Res Notes. 2017;10(5):1-6.

\section{AUTHOR AFFILIATIONS:}

Post Graduate Student

Professor \& Head

Reader

Senior Lecturer

Department of Pedodontics and Preventive Dentistry, BRS Dental College and Hospital Sultanpur, Barwala

${ }^{*}$ Corresponding Author:

Dr Pooja Chauhan

H.no-976 EE

Sec-8 U.E.

Kurukshetra Haryana

Pin code- 136118
For article enquiry/author contact details, e-mail at: editor.ihrj@gmail.com,editor@ihrjournal.com 